\title{
Spitzer sues drug giant for deceiving doctors
}

\section{Meredith Wadman, Washington}

Eliot Spitzer, the politically ambitious attorney-general of New York state who has made his name pursuing fraudsters on Wall Street, has found a new target: drug companies who do not publicize negative research results.

On 2 June, Spitzer's office sued GlaxoSmithKline (GSK) for allegedly suppressing negative results of trials that tested the safety and efficacy of Paxil, its leading antidepressant drug, in young people.

Spitzer's action is a novel and - for the pharmaceutical firms - potentially troubling incursion into a realm normally regarded as the province of the federal Food and Drug Administration (FDA).

He alleges that British-based GSK flouted New York's tough consumer-fraud law by "misrepresenting, concealing and otherwise failing to disclose to physicians" the negative results of four studies. These reported that Paxil, also known as paroxetine, was no more effective than a placebo for depressed young people, Spitzer's suit says, and that it might even increase the risk of suicide in this group.

Not only did the company fail to warn doctors of Paxil's risks, the suit contends, it promoted the drug to physicians for use in children and adolescents. The suit cites a 1998 internal company memo which said that in light of the poor study results, the company's "target" was to "effectively manage the dissemination of these data in order to minimize any potential negative commercial impact". It says that the company also gave its salespeople a memo stating that "Paxil demonstrates remarkable efficacy and safety in the treatment of adolescent depression". Attached to the memo, the suit says, was the one published study that showed some positive results for Paxil in the treatment of paediatric depression.

"GSK misled and deceived physicians and consequently the patients who relied on their professional judgment," the suit alleges. It estimates that Paxil was prescribed to some 2.1 million US youngsters in 2002, earning about $\$ 55$ million for the company that year. The drug lost US patent protection in 2003 and now faces stiff generic competition.

Tom Conway, the chief lawyer on the case in Spitzer's office, says: "It is fraudulent practice for a pharmaceutical manufacturer to release positive information while suppressing negative information. The facts of this case illustrate this principle perfectly, in our minds."

But GSK's chief executive, Jean-Pierre Garnier, immediately denied the charges. He told the Wall Street Journal that the US legal system is "out of control" and "is becoming an outrageous cost of doing business".

The company said in a statement that the 1998 memo "is inconsistent with the facts

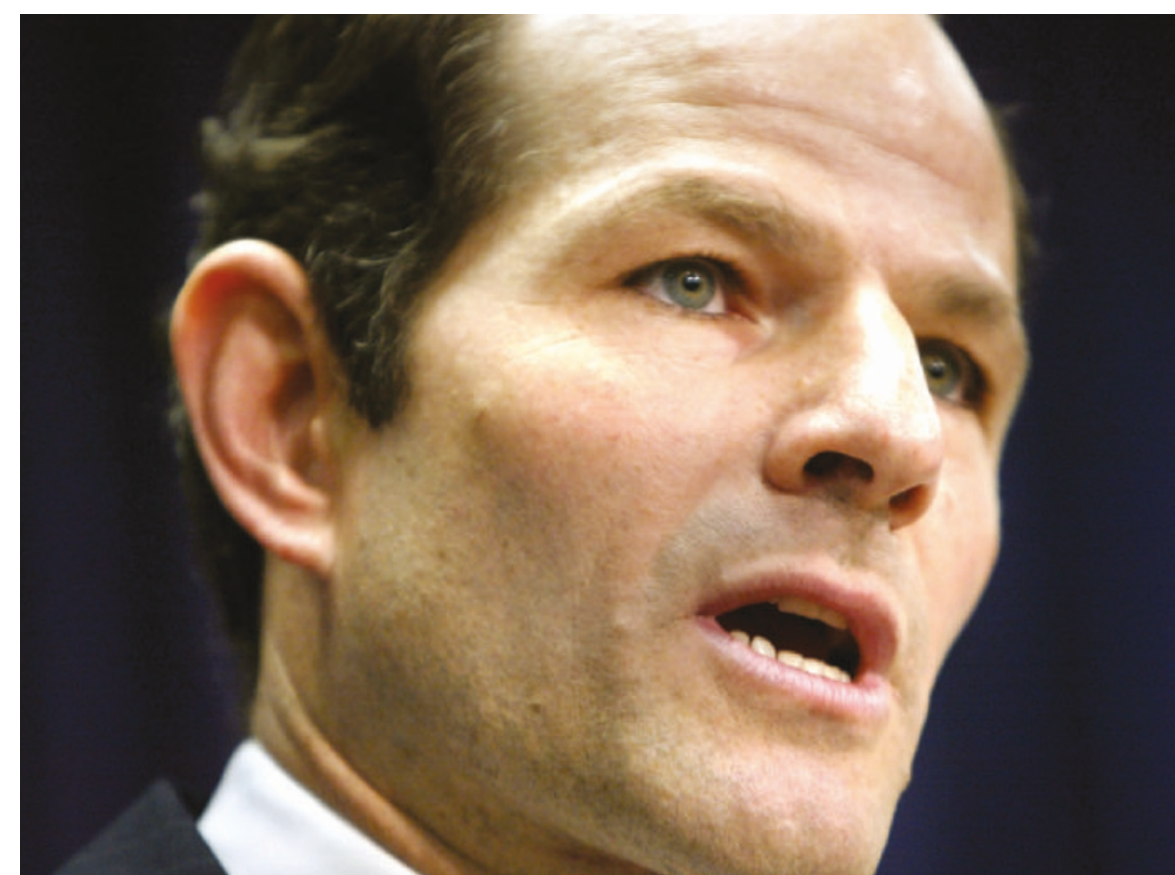

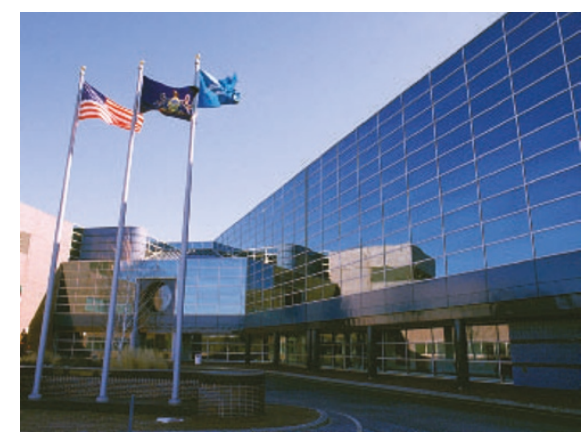

and does not reflect the company position". The statement says GSK has acted responsibly: "All paediatric studies have been made available to the FDA and regulatory agencies worldwide." Spokeswoman Mary Anne Rhyne added: "Data from paediatric studies of Paxil have been communicated publicly in more than two dozen presentations at major medical meetings."

Paxil has been approved by the FDA for use in adults with depression - but not children and adolescents. In Britain the drug is marketed as Seroxat, and in June 2003 the Department of Health, concerned about suicide risks, prohibited doctors from prescribing it to children under 18 . The same month, the FDA recommended that it should not be prescribed to depressed young people.

However, if a drug has been approved for one condition, American doctors may then prescribe it for any complaint in any patient; this is called "off-label" use. Federal law does not require companies to make any studies of such off-label uses available to doctors. Spitzer's office instead charges GSK with consumer fraud, under state law.

Some doctors contend that the issue that really needs to be addressed is that neither the
On a mission: New York's attorney-general Eliot Spitzer (above) has set his sights on the pharmaceutical firm GlaxoSmithKline (left).

companies nor the regulator have a well defined responsibility to publicize negative results. "It's perhaps too common for negative trials not to be submitted for publication," says Wayne Goodman, a professor of psychiatry at the University of Florida who sits on the FDA panel that evaluates psychiatric drugs. "That's not necessarily a problem if a drug is not going to make it to market. But if it is a marketed compound as in this case, then I think clinicians need access to all the available data."

David Fassler, a psychiatrist specializing in paediatric depression at the University of Vermont, adds: "If 20 studies are done, one is likely to show significance by chance. If that's the only one that gets published, and I don't know that there were 19 other studies with different results, it really skews the perception and ultimately alters clinical care."

The GSK lawsuit opens a new front in a wider war that Spitzer has declared against corporate targets. The 44-year-old Harvard Law School graduate, who became attorneygeneral in 1999, is widely believed to be preparing to campaign for governor of New York, and the cases he has launched have generated nationwide publicity. Spitzer has gone after the mutual fund industry, polluting power plants and the former New York Stock Exchange chairman Dick Grasso, whose "excessive" \$188-million compensation package Spitzer is challenging. And the current lawsuit may not be the last time the drug companies hear from Spitzer's office. "It's certainly an issue that is not going to end with this case," says Conway. 